\title{
REPRODUCTIVE ISOLATION
}

\section{IN THE HOUSE CRICKET \\ (ORTHOPTERA : GRYLLIDAE) ${ }^{1}$}

\author{
By A. S. K GHouri ${ }^{2}$ AND J. E. MCFARLANE \\ Entomology Department, \\ Macdonald College, P.Q., Canada
}

The existence of considerable geographic variation in the morphology of the field cricket, Acheta assimilis Fab., in North America has caused much confusion in its taxonomy, and although the variants are now commonly grouped into one species, the work of Fulton (1952) has shown that this solution is no longer acceptable. Fulton found that four "physiological races" of this insect which are reproductively isolated exist in North Carolina, and that although they show some average structural differences, intergradation between the races prevents the identification of specimens on morphological grounds.

The house cricket, Acheta domesticus (Linn.), is an insect with a cosmopolitan distribution but, surprisingly, has been the subject of very little work, although its availability and ease of rearing should have favoured its use as a laboratory animal. In the course of a study on the physiology of the development of this insect (Ghouri and $\mathrm{McF}$ arlane, in preparation), we have compared a strain obtained from Pakistan, where it lives in the field, with one obtained in Canada and have found rather large differences in their rates of development, among other characteristics, although morphologically they are quite similar. This report is concerned with the results of crossing ex-

${ }^{1}$ This paper is based on a thesis submitted to McGill University by A. S. K. Ghouri in partial fulfillment of the requirements for the Ph.D. degree.

${ }^{2}$ Present address: Department of Plant Protection, Government of Pakistan, Karachi. 
periments between the two strains which show that they are reproductively isolated.

\section{METHODS}

Eggs of the "Pakistani" strain were obtained from females collected near Usta Mohammad, West Pakistan, and sent to us by the Department of Plant Protection, Government of Pakistan, Karachi. ${ }^{3}$ The "Canadian" strain was collected from the basements of Macdonald College. Dr. A. B. Gurney of the U.S. National Museum, Washington, D.C., very kindly confirmed the writers' identifications.

Virgin females were obtained by segregating the sexes as soon as the ovipositors could be detected in the hoppers. Single pairs were kept in two-pound ointment jars and groups of two or more pairs in one-gallon candy jars.

Crossing experiments were laid according to the plans shown in Tables I and II. Oviposition dishes containing moist sand were provided after 4 to 5 days and thereafter on alternate days until the female died. All eggs laid by each female were counted and incubated. The spermathecae of a number of females were examined for sperms at various intervals ranging up to two months after the experiments were begun.

\section{OBSERVATIONS}

The results of the crossing experiments are shown in Table I. The number of eggs laid in crosses within a strain, as shown in the table, does not represent the total egg production of the females, but only the number of eggs examined in order to establish that development was taking place.

The eggs laid in crosses between individuals of the same strain and in the stock cultures usually hatched, whereas eggs laid in crosses between the strains invariably failed to develop and died 4 to 6 days after incubation. The spermathecae of 9 females in the latter crosses, examined at different intervals during the active oviposition period of stock females of similar age, were devoid of sperms,

${ }^{3}$ We are grateful to the Department of Plant Protection for supplying eggs of the Pakistani strain. 


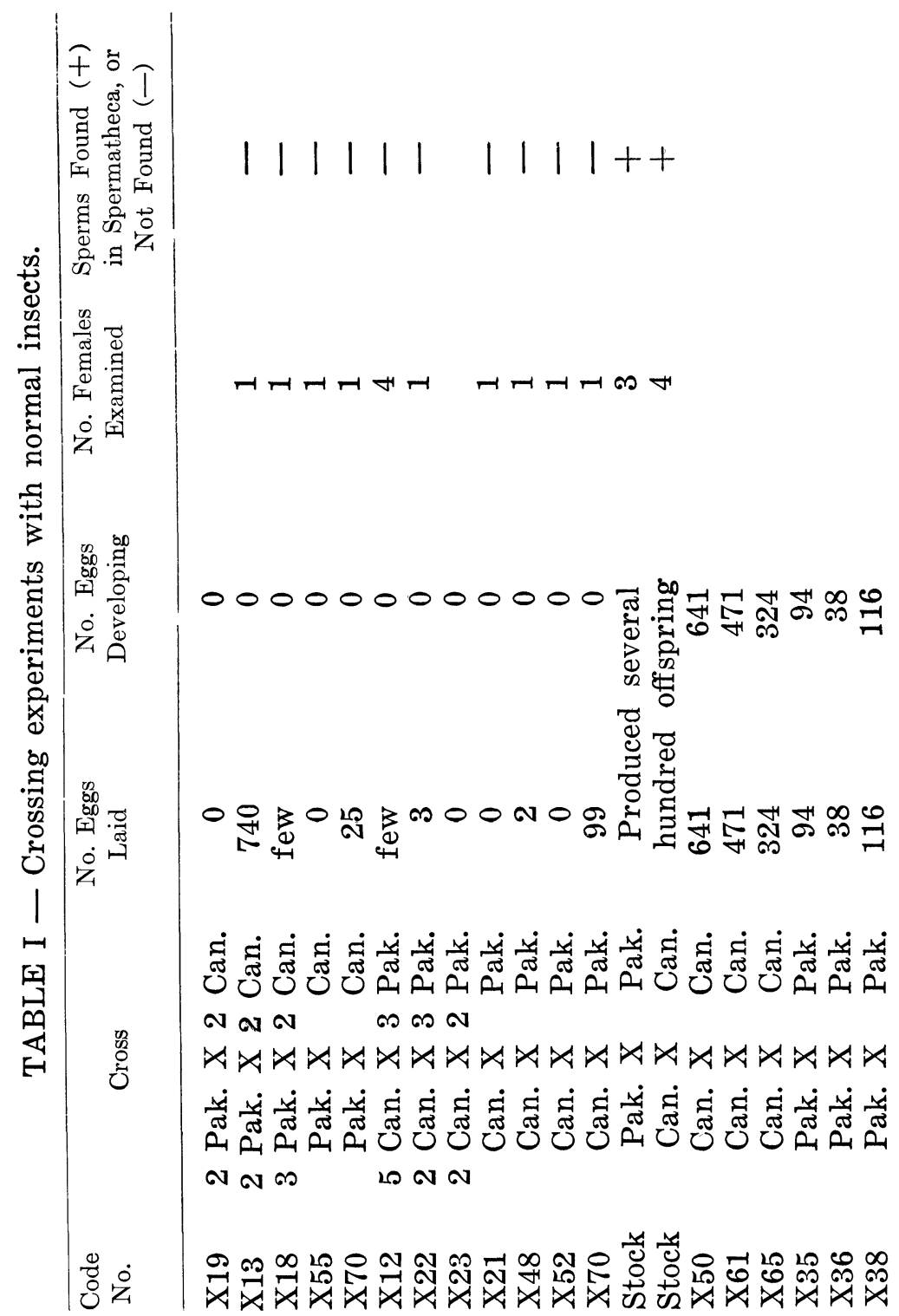


whereas the spermathecae of females in the former crosses invariably contained sperms.

Although the ovaries of females in the crosses between the strains were apparently normal, containing large numbers of eggs, these females laid a smaller number of eggs than did the females mated with males of the same strain. A female of the Canadian strain generally withheld her eggs until the last days of her life. On the other hand, Pakistani strain females mated to Canadian strain males laid eggs comparatively earlier than the Pakistani females mated to Pakistani males.

Individuals of the two strains are not separable by any consistent structural differences (their morphology has, however, been far from adequately studied, and it is quite possible that obvious differences do exist); however, the strains may still be distinguished by average differences in appearance and behaviour. The average size of the body, ovipositor, the genital openings and spermatophores of the Canadian strain adults are larger than those of the Pakistani strain. The color of the Pakistani strain adults varies from light brown with distinct markings on the head to very dark brown with scarcely perceptible markings, whereas the adults of the Canadian strain are generally light brown and do not show as much variation (both light and dark Pakistani adults were used in the crosses). Individuals of the Canadian strain are docile and seldom take to wing; on the other hand, adults of the Pakistani strain are comparatively active, and have been observed to fly as many as 50 yards at a stretch.

In spite of the mating sounds and courtship of the males (as described by Khalifa, 1950), neither the Pakistani nor the Canadian strain females showed interest in the males of the other strain. In the crosses, females of the Canadian strain often devoured the smaller males of the Pakistani strain.

\section{EFFECT OF REMOVAL OF TEGMINA OF MALES}

The stridulation of the male cricket has commonly been considered to be important in attracting the females. 
Species differences in the sounds made by the male are frequently detectable by the human ear, and Fulton (1952)

TABLE II-Crossing experiments after removal of the tegmina of the males at the base, wings left intact.

\begin{tabular}{lccr}
\hline $\begin{array}{c}\text { Code } \\
\text { No. }\end{array}$ & Cross & $\begin{array}{r}\text { Eggs Developed } \\
(+) \text { or Failed } \\
\text { to Develop (-) }\end{array}$ & $\begin{array}{r}\text { Found }(+) \\
\text { Spermath } \\
\text { or Not } \\
\text { Found }\end{array}$ \\
\hline & & & \\
C1 & Canadian X Canadian & + & + \\
C2 & Canadian X Canadian & - & \\
C3 & Canadian X Pakistani & - & \\
C4 & Canadian X Pakistani & - & \\
C5 & Pakistani X Canadian & - & \\
C6 & Pakistani X Canadian & - & \\
C7 & Pakistani X Pakistani & &
\end{tabular}

has characterized one of his races of the field cricket on the basis of its song. It seemed possible that the mating sounds of the male were responsible for the unattractiveness of the males to the females of the other strain of $A$. domesticus, although no differences between the strains were apparent. The tegmina of the males of both strains were accordingly severed at the base, leaving the wings intact (the removal of the tegmina did not appear to affect the normal activities of the males), and crossing experiments were carried out as shown in Table II.

Females mated with males of the same strain laid fertilized eggs and the spermatheca of one female was found to contain sperms, whereas females mated with males of the other strain laid eggs which invariably failed to develop, and no sperms were found in the spermatheca of the one female examined. Thus the stridulation of the participating male is not necessary for copulation (or, more precisely, insemination), nor is it the sole discouragement to copulation in crosses between strains. 


\section{Discussion}

These crossing experiments have shown that the Pakistani and Canadian strains of $A$. domesticus are reproductively isolated, and therefore are actually separate species, as defined biologically (Mayr et al., 1953).

In his crossing experiments with the races of $A$. assimilis, Fulton (1952) found that while insemination always took place, eggs laid by the females invariably failed to hatch. He concluded that hybrids were not produced either because the eggs were not fertilized or because the zygotes were not viable. With the two strains of $A$. domesticus, however, reproductive isolation consists in a failure of insemination to take place. It is possible that the strains of $A$. domesticus are not isolated at the genetic level or at the level of fertilization that separates the races of $A$. assimilis; however, attempts to achieve artificial insemination or fertilization have not been successful, due to technical difficulties.

Although there can be little doubt that geographic isolation has led to the differences between the Pakistani and Canadian strains, it would be of interest to discover the mechanism which is responsible for their isolation when brought together. Behavioural differences, in the broad sense, are obviously involved, and these may have to do with actions during courtship or perhaps with the odour of the male. In A. assimilis, Fulton (1952) has found that two "races" may occupy the same habitat, and the possibility that a more intensive study of both species groups will show that geographic isolation is not essential in speciation makes a study of the mechanism of isolation very much worthwhile.

The Pakistani and Canadian "strains" of A. domesticus are two distinct species, but, as has been pointed out by Gurney (1951) and Hubbell (1956) for A. assimilis, no practical purpose will be served, at the present stage of our knowledge of these crickets, by creating a new specific name. It will be desirable, however, to maintain a distinction between the species by giving each a geographic designation. 


\section{Litgrature Cited}

Fultow, B. B.

1952. Speciation in the field cricket. Evolution, 6: 283-295.

Ghouri, A. S. K. and McFarlane, J. E.

1957. Observations on the development of crickets. Can. Ent. In press. GuRneY, A. B.

1951. The names of the field and house crickets. J. Econ. Ent., 44: 611. HUBBelL, T. H.

1956. Some aspects of geographic variation in insects. Ann. Rev. Ent., 1 : 71-88.

Khalifa, Z.

1950. Sexual behavior in Gryllus domesticus L. Behaviour, Leiden, 2: 264-74.

Mayr, E., Linsley, E. G. and Usinger, R. L.

1953. Methods and principles of systematic zoology. New York. N.Y., McGraw-Hill Book Co. 

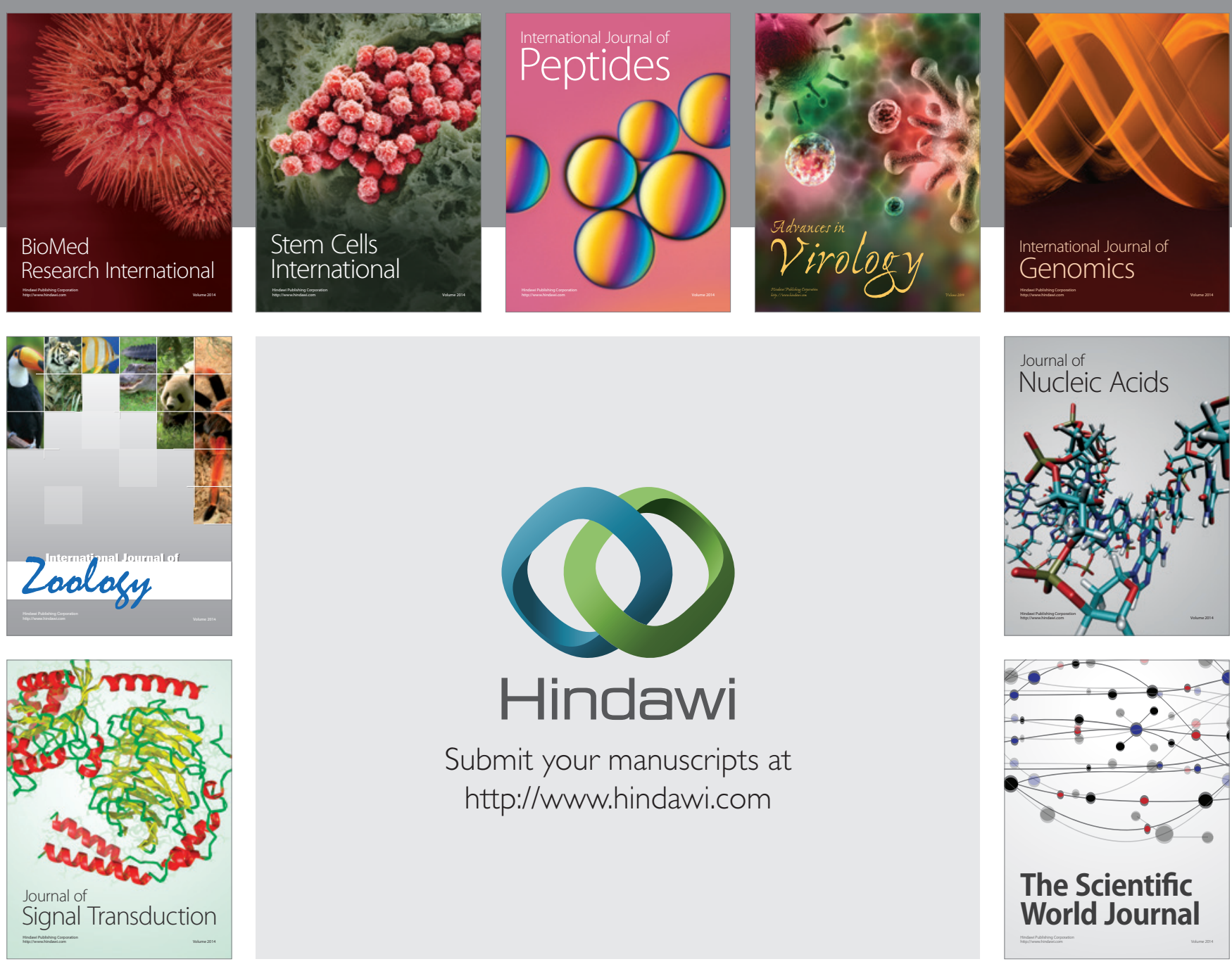

Submit your manuscripts at

http://www.hindawi.com
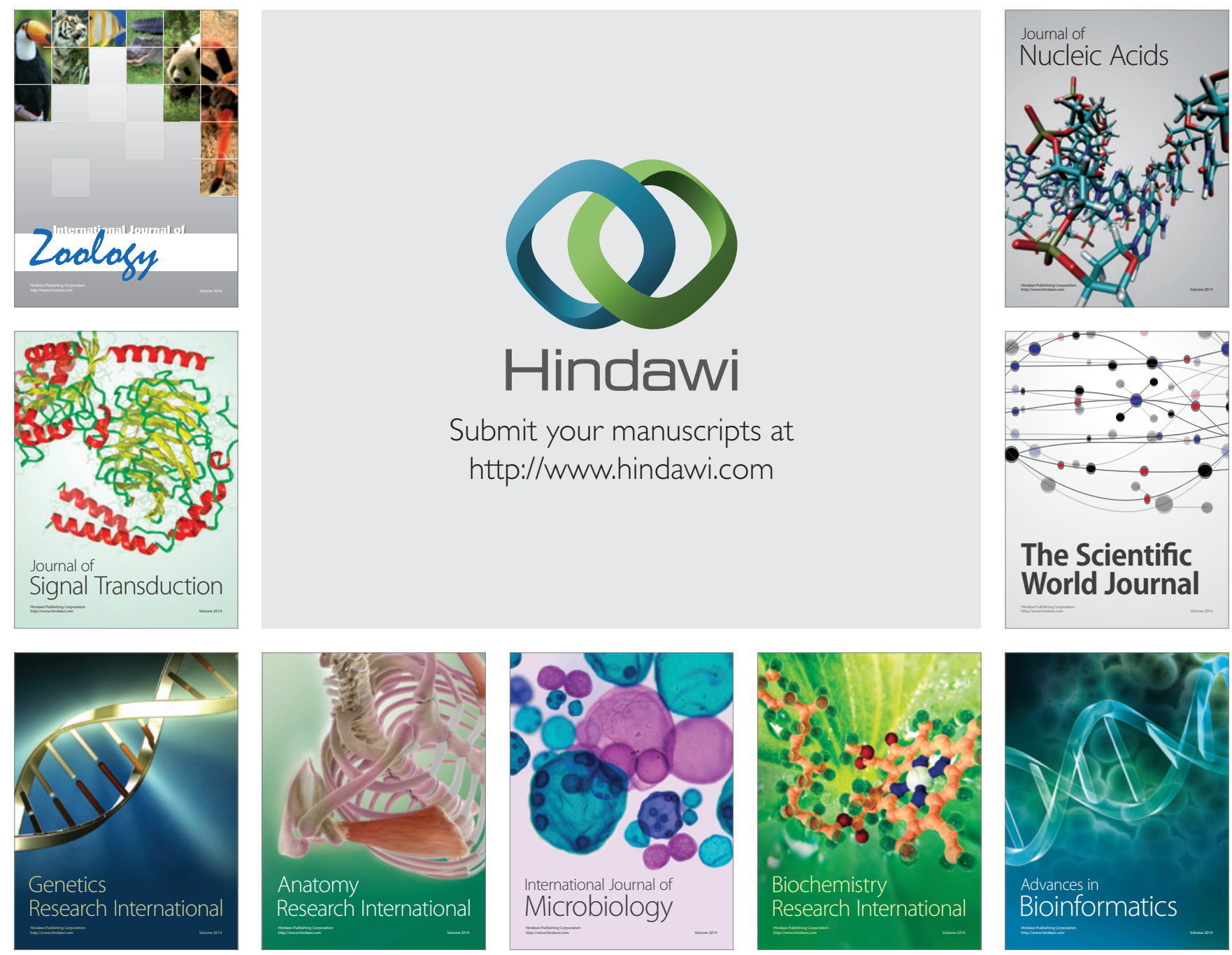

The Scientific World Journal
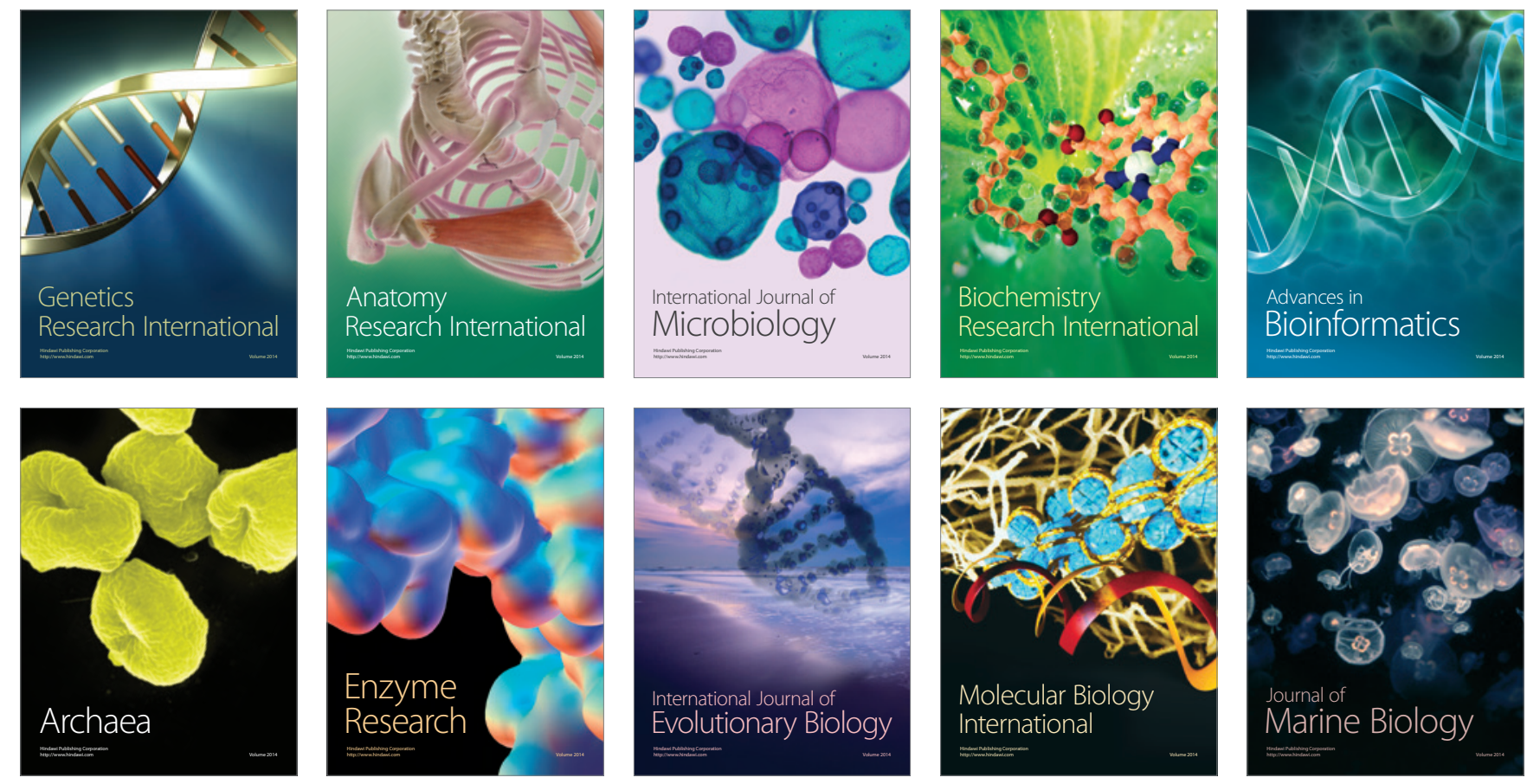